Research Article

\title{
Knowledge on Hypertension and Self-Care Practice among Adult Hypertensive Patients at University of Gondar Comprehensive Specialized Hospital, Ethiopia, 2019
}

\author{
Chanyalew Worku Kassahun (D), Ayele Asasahegn, Desalegn Hagos, Elshaday Ashenafi, \\ Firegenet Tamene, Getachew Addis, and Kidist Endalkachew
}

Department of Comprehensive Nursing, College of Medicine and Health Sciences, University of Gondar, Gondar, Ethiopia

Correspondence should be addressed to Chanyalew Worku Kassahun; chanyalewworku@gmail.com

Received 11 July 2019; Revised 27 March 2020; Accepted 3 April 2020; Published 21 April 2020

Academic Editor: Tomohiro Katsuya

Copyright (c) 2020 Chanyalew Worku Kassahun et al. This is an open access article distributed under the Creative Commons Attribution License, which permits unrestricted use, distribution, and reproduction in any medium, provided the original work is properly cited.

\begin{abstract}
Background. Patients with hypertension need to be aware of various aspects of hypertension and exercise self-care. But, there is limited information regarding this issue. Objective of the Study. This study was designed to assess knowledge on hypertension and self-care practice among adult hypertensive patients in the University of Gondar Comprehensive Specialized Hospital, Ethiopia. Materials and Methods. Descriptive cross-sectional study was conducted among 384 hypertensive patients from April to May 2019. The study participants were selected using a systematic random sampling technique. Data were collected using a pretested interviewer-administered questionnaire. Descriptive statistics such as percentage and frequency of patients' knowledge on hypertension and their self-care practice were computed. Cross-tabulation was used to see the frequency and percentage of selected sociodemographic variables and knowledge level with self-care practice subscales. Finally, the results were summarized and presented in texts, figures, and tables. Results. Among the study participants, 215 (56\%) and 228 (59.4\%) had good knowledge and self-care practice towards hypertension, respectively. The participants who had good knowledge had good self-care practice frequency. Conclusions. In this study, knowledge on hypertension was low, while self-care practice was moderate on the self-care interventions. Hence, increasing patients' awareness and intervention on medication adherence, low salt diet consumption, physical activity, weight management, cigarette smoking cessation, and alcohol consumption reduction is important.
\end{abstract}

\section{Background}

More than $80 \%$ of the burden of hypertension in low-income and middle-income countries is because of the lack of information and poor self-care practice [1]. Lack of knowledge about hypertension is a major challenge in controlling hypertension. To reduce this burden, patients have to be counseled on lifestyle changes when they visit their health facility and take measures regarding self-care [2-4]. The selfcare involves medication adherence, eating low-fat diet, regular physical exercise, limiting alcohol consumption, not smoking, weight reduction, self-monitoring of blood pressure (BP), regular health care visit, and reducing stress [5-10].
In a study conducted in Saudi Arabia, around $68 \%$ of patients knew their target BP level [11], while around $70 \%$ of patients did not know their BP level in Asia [12]. In South India, $52.4 \%$ of hypertensive patients had average or good knowledge [13], and $14 \%-56 \%$ were aware of hypertension in Nepal [14]. On the other hand, $82 \%$ of patients did not know about hypertension and $92.2 \%$ had inadequate knowledge on hypertension in Canada and Sri Lanka, respectively $[15,16]$. In Botswana, more than $96 \%$ of patients responded as reducing smoking and stress can prevent hypertension, but almost equal proportion of participants were knowledgeable about alcohol restriction (65.2\%), dietary restriction (66.3\%), and physical exercise [17]. In Addis Ababa, Ethiopia, $43.6 \%$ hypertensive patients had good 
knowledge about hypertension [18], 9.2\% knew the ideal BP, and $67.7 \%$ believed that exercise can reduce BP in a study conducted in Jimma University [19].

In India, $62.9 \%$ of the study participants had unfavorable self-care practice [20]. But, in Jeddah, Saudi Arabia, the selfcare practice ranged from $31.2 \%$ to $83.7 \%$ in each self-care subscales [11]. In a study conducted in Western Nepal, more than $55 \%$ of patients involved in their own care in each selfcare practice components $(70 \%$ did not take alcohol/quit smoking, $80.6 \%$ took low fat and salt diet, $69.7 \%$ monitored their BP regularly, 58.2\% reduced their stress, and $85 \%$ used medication regularly) [21]. In another study conducted in outreach clinic of South India indicated that $11.4 \%, 49.2 \%$, and $39.2 \%$ hypertensive patients had good, average, and poor self-care practice, respectively [13]. A study conducted in Northwestern Nigeria showed that majority of the participants had inadequate self-care practice [22]. In studies conducted in Ethiopia, 51\% of hypertension patients had poor self-care practice in Dessie town [23], and $51.5 \%$ of study participants had good self-care practice in Addis Ababa [18]. In addition, only $1.5 \%$ of participants smoked and $94.6 \%$ followed salt restrictions in Jimma University [19].

Nevertheless, limited studies have been conducted on this issue in Ethiopia, in the study area in particular. Therefore, this study is designed to assess knowledge on hypertension and self-care practice among adult hypertensive patients.

\section{Materials and Methods}

2.1. Study Design, Area, and Period. This hospital-based descriptive cross-sectional study design was conducted at the University of Gondar Comprehensive Specialized Hospital (UoGCSH) from April to May 2019. UoGCSH provides different specialized services in four major departments: the Pediatrics, Surgery, Gynecology and Obstetrics, and Internal Medicine. It also has its own chronic disease such as hypertensive patients follow-up service. Hypertensive patients are attending their follow-up monthly. On average, 450 adult hypertensive patients are attending their follow-up in the hospital per month [24].

2.2. Study Population. All adult hypertensive patients on follow-up were the source population. Hypertensive patients available during data collection period were included. Participants who have attended their follow-up less than six months and could not to be interviewed were excluded.

\section{Sample Size, Sample Technique, and Procedure}

The sample size was calculated by using a single population proportion formula:

$$
n=\frac{\left(z^{2}\right)(p)(1-p)}{d^{2}}
$$

where $n=$ sample size, $z=1.96$ at $95 \%$ confidence level, $d=5 \%$ margin of error, and $p=51.5 \%$, proportion for selfcare practice among hypertensive patient, which was taken from a study conducted at Addis Ababa [18]. Accordingly, the sample size was 384 . The study used systematic random sampling technique. Card numbers of the study participants were selected first from the log book according to their follow-up. Next, patients were selected using eligibility criteria. Then, unique numbers were given for each participant. The sampling frame was determined from the monthly patient flow, i.e., every two patients were used to select each study participants. The first person was selected by simple random sampling.

\subsection{Operational Definitions}

3.1.1. Knowledge. Participants were labeled as knowledgeable if they scored median and above and nonknowledgeable if they scored below the median. Twelve items were used to measure knowledge. The response of participants in each item was coded as "Yes" if they answered the items correctly, and "No" if they answered incorrectly. Median was calculated from items which were answered correctly.

3.1.2. Self-Care Practice. Patients report on their engagement with any kind of recommended self-care activities. Participants were categorized as having good practice if they scored median and above and having poor practice if they scored below the median [25]. Self-care practice was measured by Hypertension Self-Care Activity Level Scale Effects (H-SCALE), which has six outcome domains: medication adherence (3 items): responses range from 0 to 21 , and participants who reported that they followed the 3 recommendations on 7 out of 7 days were considered adherent $($ score $=21)$. Low-salt diet (12 items): scores of 6 out of 7 days were considered adherent. Physical activity (2 items): responses range from 0 to 14 . Participants who scored 8 or better were considered adherent. Smoking ( 2 items): responses ranges from 0 to 14 , and respondents who reported 0 days were considered a nonsmoker and all others were smokers. Weight management (10 items): responses range from 10 to 50. Participants who agreed or strongly agreed with all 10 items (score $\geq 40$ ) were considered to be following good weight management practices. Alcohol (3 items): responses range from 0 to 21 . Participants who did not take any alcohol in the last 7 days or who did not drink at all were considered abstainers. All others were nonadherent.

3.2. Data Collection Instrument/Tools and Procedure. Semistructured interviewer-administered questionnaire was used to collect the data. The tool has three sections: Section I: sociodemographic information; Section II: knowledge-related questions; Section III: self-care-related questions. Knowledge on hypertension was assessed by a validated tool for hypertensive patients [26]. To measure self-care practice, Hypertension Self-Care Activity Level Effects (H-SCALE) which was used in a previous study in Jimma, Ethiopia, was 
used [27]. All questionnaires were prepared in English language and then translated to Amharic (local language), which has been used for data collection. To keep the quality of the data completeness of the questionnaire, it was checked before data entry, and EPI-data version 3.1 was used to minimize the data entry error.

3.3. Data Processing and Analysis. Data were checked for completeness, edited, and entered to EPI-data version 3.1 and exported to SPSS version 21 for analysis. The data were explored to see missing values, the shape, and distribution of the data. On the basis of this information, there are no missing values, and the data were almost normally distributed. Descriptive statistics (frequencies, percentages, mean values, and standard deviations) were calculated for demographic characteristics. Then, the percentage and frequency of patients' knowledge on hypertension and their self-care practice were computed. Cross-tabulation was used to check the frequency and percentage of selected sociodemographic variables and knowledge level with self-care practice subscales. Finally, the results were summarized and presented in texts, figures, and tables.

\section{Results and Discussion}

\subsection{Results}

4.1.1. Sociodemographic Characteristics of Hypertensive Patients. The response rate of the study was 100\%. The median age of the participants was 56 years $(S D \pm 13.6)$. Most of the respondents, 178 (46.4\%), were within the age group of 41-60 years. Majority of the respondents, 139 (36.2\%), 266 (69.3\%), and 255 (66.4\%), were housewife, lived in urban area, and married, respectively. A large proportion of the study participants, 303 (78.9\%), had no family history of hypertension (Table 1).

\subsubsection{Knowledge of Hypertensive Patients about} Hypertension. The majority, 365 (92.4\%) and 379 (98.7\%), reported that hypertension is a serious disease and regular check-ups are important, respectively. But, 144 (37.5\%) of the respondents were not aware about the normal BP level. Most of the respondents, 305 (79.4\%) and 339 (88.3\%), were aware of about the negative impact of smoking of cigarette and alcohol drinking, respectively. Around half of the respondents, 188 (49\%), knew diets that consist of low-fat milk and whole wheat bread (Table 2).

Two hundred fifteen (56\%) (95\% CI: 51\%, 60.7\%) of participants scored median and above and considered having good knowledge towards hypertension, while 169 (44\%) (95\% CI: 39.3\%, 49.0\%) scored below the median and considered having poor knowledge (Figure 1).

4.1.3. Self-Care Practice among the Respondents. Of the study participants, 228 (59.4\%) (95\% CI: 54.9\%, 64.6\%) had good self-care practice, while 156 (40.6\%) (95\% CI: 35.4\%, $45.1 \%)$ had poor self-care practice. In terms of the six domains of self-care practice, 261 (68\%), 266 (69.3\%), and 81
TABle 1: Sociodemographic characteristics of hypertensive patients.

\begin{tabular}{|c|c|c|}
\hline Variables & Frequency & Percent \\
\hline \multicolumn{3}{|l|}{ Age category (in years) } \\
\hline$<40$ & 53 & 13.8 \\
\hline $40-60$ & 178 & 46.4 \\
\hline $61-80$ & 143 & 37.2 \\
\hline$\geq 81$ & 10 & 2.6 \\
\hline \multicolumn{3}{|l|}{$\operatorname{Sex}$} \\
\hline Male & 184 & 47.9 \\
\hline Female & 200 & 52.1 \\
\hline \multicolumn{3}{|l|}{ Marital status } \\
\hline Single & 31 & 8.1 \\
\hline Married & 255 & 66.4 \\
\hline Divorced & 33 & 8.6 \\
\hline Widowed & 65 & 16.9 \\
\hline \multicolumn{3}{|l|}{ Level of education } \\
\hline Illiterate & 154 & 40.1 \\
\hline Primary education & 114 & 29.7 \\
\hline Secondary education & 54 & 14.1 \\
\hline College and above & 62 & 16.1 \\
\hline \multicolumn{3}{|l|}{ Occupation } \\
\hline House wife & 139 & 36.2 \\
\hline Husband & 56 & 14.6 \\
\hline Student & 6 & 1.6 \\
\hline Merchant & 55 & 14.3 \\
\hline Farmer & 36 & 9.4 \\
\hline Government employee & 50 & 13 \\
\hline NGO & 31 & 8.1 \\
\hline Others* & 11 & 2.9 \\
\hline \multicolumn{3}{|l|}{ Residence } \\
\hline Urban & 266 & 69.3 \\
\hline Rural & 118 & 30.7 \\
\hline \multicolumn{3}{|l|}{ Income (in Birr) } \\
\hline$\leq 500$ & 33 & 8.6 \\
\hline $501-1000$ & 71 & 18.5 \\
\hline$>1000$ & 280 & 72.9 \\
\hline \multicolumn{3}{|c|}{ Length since diagnosis (in years) } \\
\hline$\leq 5$ & 206 & 53.6 \\
\hline$>5$ & 178 & 46.4 \\
\hline \multicolumn{3}{|l|}{ Family history } \\
\hline Yes & 81 & 21.1 \\
\hline No & 303 & 78.9 \\
\hline
\end{tabular}

${ }^{*}$ Others = labor worker, pension receiver, private teacher, driver, guard, private pharmacist, priest, and sanitation worker.

(21.1\%) had adherence to medication, low-salt diet, and physical activity, respectively (Table 3 ).

In the cross-tabulation of self-care practice with knowledge level, a higher frequency of good self-care practice was observed among those who had good hypertension knowledge.

4.2. Discussion. This study was intended to determine knowledge on hypertension and its self-care practice among adult hypertensive patients at the University of Gondar Comprehensive Specialized Hospital. Based on this aim, 56\% and $59.4 \%$ had good knowledge and overall self-care practice, respectively. 
TABLE 2: Description of hypertension knowledge-related questions among hypertensive patients, $2019(n=384)$.

\begin{tabular}{|c|c|c|}
\hline Questions & Frequency & Percent \\
\hline \multicolumn{3}{|c|}{ Hypertension is a serious condition that can lead to complications } \\
\hline Yes & 365 & 92.4 \\
\hline No & 29 & 7.6 \\
\hline \multicolumn{3}{|c|}{ An individual with hypertension should go for check-ups regularly } \\
\hline Yes & 379 & 98.7 \\
\hline No & 5 & 1.3 \\
\hline \multicolumn{3}{|c|}{$\begin{array}{l}\text { It is important for a patient with hypertension to have a reliable means of blood pressure monitoring between visits to } \\
\text { their health care provider }\end{array}$} \\
\hline Yes & 370 & 96.4 \\
\hline No & 14 & 3.6 \\
\hline \multicolumn{3}{|c|}{ A blood pressure level of above $130 / 90$ is considered normal } \\
\hline Yes & 144 & 37.5 \\
\hline No & 240 & 62.5 \\
\hline \multicolumn{3}{|c|}{ A blood pressure level of less than $120 / 80$ is considered to be high } \\
\hline Yes & 154 & 40.1 \\
\hline No & 230 & 59.9 \\
\hline \multicolumn{3}{|c|}{ Smoking cigarettes has a negative effect on persons with hypertension } \\
\hline Yes & 305 & 79.4 \\
\hline No & 79 & 20.6 \\
\hline \multicolumn{3}{|c|}{ Drinking alcohol has a negative effect on persons with hypertension } \\
\hline Yes & 339 & 88.3 \\
\hline No & 45 & 11.7 \\
\hline \multicolumn{3}{|c|}{ Increased physical exercise actually decreases the blood pressure of a person with hypertension } \\
\hline Yes & 322 & 83.9 \\
\hline No & 62 & 16.1 \\
\hline \multicolumn{3}{|c|}{ A diet which contains fruits and vegetables is good for a person with hypertension } \\
\hline Yes & 301 & 78.4 \\
\hline No & 83 & 21.6 \\
\hline \multicolumn{3}{|c|}{ A diet consisting of low-fat milk and whole wheat bread is good for a person with hypertension } \\
\hline Yes & 188 & 49 \\
\hline No & 196 & 51 \\
\hline \multicolumn{3}{|c|}{ Corned beef and salted meat is good for a person with hypertension } \\
\hline Yes & 313 & 81.5 \\
\hline No & 71 & 19.5 \\
\hline \multicolumn{3}{|c|}{ A meal rich in green bananas, baked chicken, and beans is good for a person with hypertension } \\
\hline Yes & 124 & 32.3 \\
\hline No & 260 & 67.7 \\
\hline
\end{tabular}

More than half of hypertensive patients had good knowledge of hypertension in this study. This finding is similar to the study finding in South India (52.4\%) [13]. On the other hand, it is higher than studies conducted in Nepal (14\%) [14], Ethiopia (43.6\%) [18], and Canada (18.2\%) [15]. The possible reasons for the difference might be due to the study setting, sample size, and study period variation between the current study and previous studies.

In this study, almost sixty percent hypertensive patients had good self-care practice towards hypertension. This finding is higher than the studies conducted in Addis Ababa, Ethiopia (51.5\%) [18] and south India (14\%) [13]. These differences could be due to variation in residence and study period as majority of the participants were from urban in this study, which might help them to get information easily. In addition, it is the government's current agenda to work on noncommunicable diseases.

Similarly, in this study, majority of the participants had good medication adherence, which is lower than studies conducted in Saudi Arabia (83.7\%) [11] and Western Nepal (85\%) [21]. This variation might be due to the reason that majority of the participants in the current study were not knowledgeable about hypertension. In the current study, almost quadruple times of the respondents had low-salt diet adherence. This finding is lower than studies conducted in Saudi Arabia (79.3\%) [11] and Ethiopia (94.6\%) [19]. But, it is higher than the study conducted in Nigeria (18.5\%) [22]. This might be due to the variation in the study setting, sample size, and study period variation. This study also revealed that below one-third of the participants had adhered with physical activity recommendations, which is lower than the study conducted in Saudi Arabia (57.3\%) [11], but higher than study conducted in Nigeria (9.3\%) [22]. The difference could be that participants were not well educated about self-care practice towards lowsalt diet and physical activities in the current study. The current study pointed out that majority of the participants had quit smoking, which is an important aspect of self-care practice. This finding is in line with the study conducted in western Nepal (70\%), and it is lower than the study conducted in Jimma, Ethiopia (98.5\%) [19]. But, it is higher than the study conducted in Saudi Arabia (31\%) [11]. This difference could be due to majority of the participants who were from urban in the 


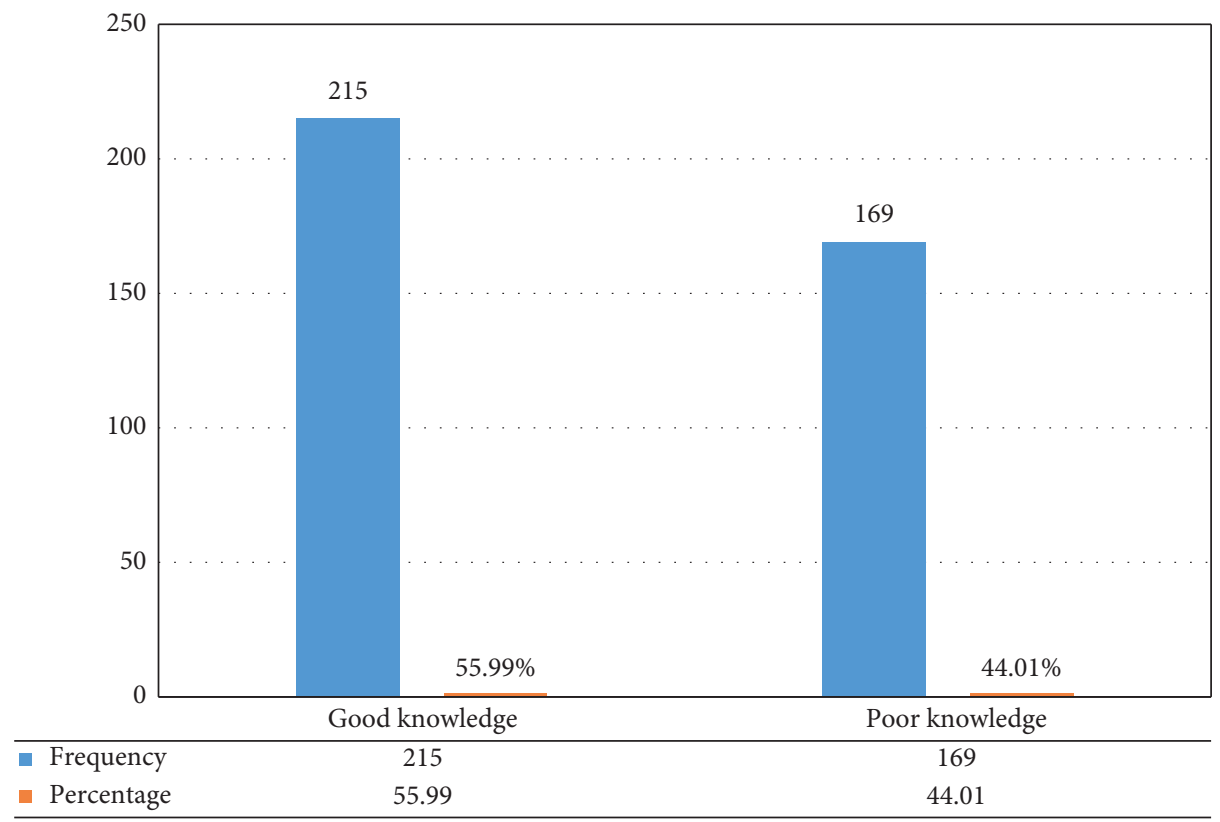

FIgURE 1: Knowledge level of the hypertensive patient, 2019.

TABle 3: Self-care practice level of hypertensive patients, 2019.

\begin{tabular}{|c|c|c|c|}
\hline \multicolumn{2}{|c|}{ Self-care practice domains } & \multirow{2}{*}{$\begin{array}{c}\text { Frequency } \\
261\end{array}$} & \multirow{2}{*}{$\begin{array}{c}\text { Percentage } \\
68\end{array}$} \\
\hline & Adherent & & \\
\hline Medication adherence & Not adherent & 123 & 32 \\
\hline \multirow{2}{*}{ Low-salt diet } & Adherent & 266 & 69.3 \\
\hline & Not adherent & 118 & 30.7 \\
\hline \multirow{2}{*}{ Physical activity } & Adherent & 81 & 21.1 \\
\hline & Not adherent & 303 & 78.9 \\
\hline \multirow{2}{*}{ Smoking } & Nonsmoker & 272 & 70.8 \\
\hline & Smoker & 112 & 29.2 \\
\hline \multirow{2}{*}{ Weight management } & Good weight management practice & 235 & 61.2 \\
\hline & Poor weight management practice & 149 & 38.8 \\
\hline \multirow{2}{*}{ Alcohol } & Abstainers & 278 & 72.4 \\
\hline & Not abstainers & 106 & 27.6 \\
\hline \multirow{2}{*}{ Overall self-care practice } & Good & 228 & 59.4 \\
\hline & Poor & 156 & 40.6 \\
\hline
\end{tabular}

current study, but the reverse is true in Saudi Arabia where life style and urbanization affect smoking condition. This study also ascertained that more than half of the study participants had good weight management practice, which is comparable to the study conducted in Saudi Arabia (59.9\%) [11].

\section{Clinical Relevance of the Study}

As shown above and mentioned by different literatures, understanding the level of patients knowledge on hypertension and its self-care measures are an important topic to be addressed to fill treatment gaps. The current study points out that the patient's involvement in their own care can bring good clinical outcome. This will have an impact to avert hypertension-related complication and mortality.

\section{Conclusions}

The level of knowledge and self-care practice among hypertensive patients were relatively low, and almost $80 \%$ of participants had poor self-care practice in the physical activity domain. Hence, giving focus on awareness of hypertension and self-management of hypertensive patients are important. Furthermore, a large follow-up study is recommended.

\section{Data Availability}

The datasets generated and/or analyzed during the current study are not publicly available due to some privacy reasons, but part of the raw dataset will be available from the corresponding author upon reasonable request. 


\section{Additional Points}

Since the study assessed the perceived patient's report, it might underestimate or overestimate the result.

\section{Ethical Approval}

Ethica clearance was obtained from the ethical review committee of the School of Nursing, College of Medicine and Health Sciences, University of Gondar. Official permission was obtained from the study site.

\section{Consent}

Oral informed consent was obtained from study participants.

\section{Conflicts of Interest}

The authors declare that they have no conflicts of interest.

\section{Acknowledgments}

The authors would like to thank the University of Gondar Comprehensive Specialized Hospital's hypertensive chronic disease follow-up coordinators and staff who provided preliminary information and support during data collection. And also, the authors would like to thank the study participants who provided the information.

\section{References}

[1] D. F. J. Markenson, L. Chameides, P. Cassan et al., "First aid 2010 American heart association and American red cross guidelines for first aid," Circulation, vol. 122, no. supplementry_3, pp. S934-S946, 2010.

[2] M. T. Brown and J. K. Bussell, Eds., Mayo Clinic Proceedings, vol. 86, no. 4, pp. 304-314, 2011.

[3] S. Baliz Erkoc, B. Isikli, S. Metintas, and C. Kalyoncu, "Hypertension knowledge-level scale (HK-LS): a study on development, validity and reliability," International Journal of Environmental Research and Public Health, vol. 9, no. 3, pp. 1018-1029, 2012.

[4] H. Hu, G. Li, and T. Arao, "Prevalence rates of self-care behaviors and related factors in a rural hypertension population: a questionnaire survey," International Journal of Hypertension, vol. 2013, Article ID 526949, 8 pages, 2013.

[5] H.-R. Han, H.-J. Song, T. Nguyen, and M. T. Kim, "Measuring self-care in patients with hypertension: a systematic review of literature," Journal of Cardiovascular Nursing, vol. 29, no. 1, pp. 55-67, 2014.

[6] L. J. Appel, T. J. Moore, E. Obarzanek et al., "A clinical trial of the effects of dietary patterns on blood pressure," New England Journal of Medicine, vol. 336, no. 16, pp. 1117-1124, 1997.

[7] F. M. Sacks, L. P. Svetkey, W. M. Vollmer et al., "Effects on blood pressure of reduced dietary sodium and the Dietary Approaches to Stop Hypertension (DASH) diet," New England Journal of Medicine, vol. 344, no. 1, pp. 3-10, 2001.

[8] G. A. Kelley and K. S. Kelley, "Progressive resistance exercise and resting blood pressure: a meta-analysis of randomized controlled trials," Hypertension, vol. 35, no. 3, pp. 838-843, 2000 .
[9] M. Roerecke, J. Kaczorowski, S. W. Tobe, G. Gmel, O. S. Hasan, and J. Rehm, "The effect of a reduction in alcohol consumption on blood pressure: a systematic review and meta-analysis," The Lancet Public Health, vol. 2, no. 2, pp. e108-e20, 2017.

[10] J. He, P. K. Whelton, L. J. Appel, J. Charleston, and M. J. Klag, "Long-term effects of weight loss and dietary sodium reduction on incidence of hypertension," Hypertension, vol. 35, no. 2, pp. 544-549, 2000.

[11] L. A. Bakhsh, A. A. Adas, M. A. Murad et al., "Awareness and knowledge on hypertension and its self- care practices among hypertensive patients in Saudi," Annals of International Medical and Dental Research, vol. 2, no. 5, 2017.

[12] VA, "Knowledge of hypertensive patient," Asian Journal of Research in Biological and Pharmaceutical Sciences, vol. 2, no. 4, pp. 183-188, 2014.

[13] N. Joseph, M. Chiranjeevi, S. Sen, P. Singh, M. Saini, and S. Beg, "Awareness on hypertension and its self-management practices among hypertensive patients attending outreach clinics of a medical college in south India," Kathmandu University Medical Journal, vol. 14, no. 55, pp. 202-209, 2016.

[14] A. Bagale, "Awareness of hypertensive patients about disease, self-care and complication," Saudi Journal of Medical and Pharmaceutical Sciences, vol. 2, no. 4, pp. 65-68, 2016.

[15] M. Bilal, A. Haseeb, S. S. Lashkerwala et al., "Knowledge, awareness and self-care practices of hypertension among cardiac hypertensive patients," Global Journal of Health Science, vol. 8, no. 2, p. 9, 2016.

[16] U. Seneviratne, P. Rajapakse, R. Pathirana, and T. Seetha, "Knowledge, attitude, and practice of epilepsy in rural Sri Lanka," Seizure, vol. 11, no. 1, pp. 40-43, 2002.

[17] L. Zungu and F. Djumbe, Knowledge and Lifestyle Practices of Hypertensive Patients Attending a Primary Health Care Clinic in Botswana, Institutional Repository, Botswana, South Africa, 2013.

[18] S. M. Ahmed, Assessment of Knowledge, Self-Care Practice and Associated Factors towards Hypertension Among Hypertensive Patients in Public in Hospital Addis Ababa City Administration, Addis Ababa University, Addis Ababa, Ethiopia, 2016.

[19] S. Tesema, B. Disasa, S. Kebamo, and E. Kadi, "Knowledge, attitude and practice regarding life style modifications of hypertensive patients at Jimma University Ethiopia," Research article open access, 2016.

[20] A. Dasgupta, S. Sembiah, B. Paul, A. Ghosh, B. Biswas, and N. Mallick, "Assessment of self-care practices among hypertensive patients: a clinic based study in rural area of Singur, West Bengal," International Journal of Community Medicine and Public Health, vol. 5, no. 1, pp. 262-267, 2017.

[21] R. Karmacharya and K. Paudel, "Awareness on hypertension and its self-management practices among hypertensive patients in Pokhara, western Nepal," Janapriya Journal of Interdisciplinary Studies, vol. 6, pp. 110-120, 2017.

[22] V. Boima, A. D. Ademola, A. O. Odusola et al., "Factors associated with medication nonadherence among hypertensives in Ghana and Nigeria," International Journal of Hypertension, vol. 2015, Article ID 205716, 8 pages, 2015.

[23] S. Ademe, F. Aga, and D. Gela, "Hypertension self-care practice and associated factors among patients in public health facilities of Dessie town, Ethiopia," BMC Health Services Research, vol. 19, no. 1, p. 51, 2019.

[24] University of Gondar Comprehensive Specialized Referral Hospital, HMIS Office Data, University of Gondar Comprehensive Specialized Referral Hospital, Gondar, Ethiopia, In press, 2019. 
[25] D. Daniel and R. S. Kamal, "Assessment of knowledge, attitude and practice of hypertensive patients towards the nonmedical management of hypertension in bishoftu general hospital," The Pharmaceutical and Chemical Journal, vol. 4, no. 1, p. $48,2017$.

[26] J. Warren-Findlow and R. B. Seymour, "Prevalence rate of hypertension self-care activities among African Americans," Journal of the National Medical Association, vol. 103, no. 6, 2011.

[27] B. Tesfaye, D. Haile, B. Lake, T. Belachew, and H. Abera, "Uncontrolled hypertension and associated factors among adult hypertensive patients on follow-up at jimma university teaching and specialized hospital," Research Reports in Clinical Cardiology, vol. 8, pp. 21-22, 2017. 